\title{
Contributions of Formal Education to Social Development - What do we Know on the Basis of Research Evidence?
}

Tuomas Takala*

Abstract

This article gives an overview, on the basis of existing synthesis reports and articles, of the current state of knowledge on the role of formal education in promoting social development.

The existing evidence is contrasted with simplistic assumptions that abound in the political discussions on education and development. At the same time, the limitations of the potential of research to serve as a guide

to policy decisions are also acknowledged.

\begin{abstract}
Introduction
The present examination of education as a contributor to social development needs to begin with a conceptual question. It is often taken for granted, particularly in non-academic writing and speech, that formal education (schooling) is "good in itself". Conceptually, this reflects the view that being more educated is inherently better than being less educated, both at the individual level and in populations at large. In such a view, education is akin to health - it is commonly held that health is better than sickness. Notably, the tenet that education as such has an intrinsic value disregards the questions concerning the content of education - although in a more concrete analysis most people would not accept that e.g. instilling xenophobic attitudes in the minds of pupils represents a positive value.

The alternative view is that education should not be seen as having an intrinsic value, but only an instrumental one: i.e. education has a value insofar as it can be a means to promote other goals of social development (e.g. health). In this respect, the contribution of education is bound to be quite variable in different contexts and also importantly dependent on the quality of education and its relevance vis-à-vis the socio-cultural context. The actual contribution of education to social development can only be investigated through research, and some aspects of this research task are very challenging.

This article gives an overview, on the basis of existing synthesis reports and articles, of the current state of knowledge on the role of formal education in promoting social development. Most of the research evidence deals with either education in general, or with

Professor of Comparative Education, Department of Education, University of Tampere, Finland, Email:m.tuomas.takala@uta.fi
\end{abstract}


2 Tuomas Takala

primary education only. The existing evidence is contrasted with simplistic assumptions that abound in the political discussions on education and development. At the same time, the limitations of the potential of research to serve as a guide to policy decisions are also acknowledged.

\section{Concept of education as a human right}

When education is referred to as a "human right", it is usually operationalized as provision of primary education, which is compulsory and free of charge, for all children. This definition was first laid down in the Universal Declaration of Human Rights, adopted by the United Nations in 1948. It has subsequently been endorsed in numerous international treaties and other documents, e.g. the Convention on the Rights of the Child (1989) and the documents of the international Education for All conferences (World declaration...,1990 and Dakar Framework...,2000).

Not much critical analysis has been undertaken on the rationale behind the education as a human right notion. In the title of an article published in 1986, Mark Bray formulated the fundamental issue aptly: "If universal primary education is the answer, what is the question?" His analysis raised the question that if primary education is a right, how is it then also regarded as something that should be made compulsory? Or should parents, or perhaps children themselves, also have the right to refuse, or drop out of, school if the the kind of education that is being provided is not deemed worthwhile by them? (Bray, 1986).

This kind of critical voices were soon thereafter overwhelmed by the global Education for All discourse. A recent exception is the book by John Oxenham that provides a discussion of the notion of adult literacy as a "human right". The author refers to the "experience of instructional methods that focused on the skills of literacy without regard to the meaning and relevance to the adult learners' interests and conditions. The failure of such methods to retain large proportions of their learners - let alone make them literate - led to the development of approaches that demonstrated more readily the usefulness and other values of literacy. Literacy needed to be combined with religious interests, economic improvement, social action of political empowerment, before it could hold most of its adult learners sufficiently long for them to master its skills. In short, for most illiterate adults, literacy in itself appears not to be an absolute value or passionately-pursued right, but very much an instrument to other ends" (Oxenham, 2008, p. 29-30).

An additional critical point towards the human rights discourse is that in this discourse "education" has tended to become synonymous with literacy and formal schooling: if a person is not literate/ has not attended school, s/he is regarded as having been denied one of the basic human rights. A consequence of such a view is that non-literate cultural traditions and their modes of education are devalued - extreme expressions of this are references to illiteracy as "ignorance" or even as a "disease" (Jones, 1988 , p. $75,106-116)$. The concept of formal education as a human right also sidelines the fact that schooling in reality often is a humiliating experience for the pupils, for instance due to use of an alien language in teaching, physical punishment or sexual abuse.

\section{Education as a means to promote social development}

The following quotation is extracted from a document published in 1999 by UNICEF :

"Education is the single most vital element in combating poverty, empowering women, promoting human rights and democracy, protecting the environment and controlling population growth" (quoted in Hall \& Midgley, 2004, p. 153).

Quotations with similar content and tone could easily be found from a large number of international and national documents that deal with issues of education and development. They demonstrate a remarkable belief in the potential 


\section{Contributions of Formal Education to Social Development $\mid 3$}

of education, often linked with lack of attention to the institutional and structural factors in society that either facilitate or block the potential effects of education. Around the belief in education as a socio-economic panacea a global political consensus has been built (e.g. Chabbott \& Ramirez, 2000) - who could be against provision of more education? This consensus could not be sustained if the complexity of the issues was made explicit by reference to the structural and institutional factors in the broader social context of education (e.g. land ownership, gender biases in legislation) (Takala, 1998). Of course it is still possible to argue that education has an empowering potential, to put in motion political processes which then will transform the existing conditions in the larger society. But such an argument would need to be qualified by examining the question: what kind of education can have such potential?

It is also notable that parents' views of the potential benefits of schooling, which they compare with the direct and indirect costs of school attendance, may be considerably more realistic than the global political discourse (e.g. findings of the study by Boyle et al., 2002). Experiences of countries (e.g. Uganda and Malawi in the 1990s) that have undergone an explosive growth of school enrollments, due to abolition of school fees and other proEFA policies, show that after an initial period of high expectations attached to the growing educational opportunities, disillusionment has set in as the quality and relevance of schooling are questionable (Fredriksen, 2009, p. 13-15).

How can the contribution of education to development be researched?

In terms of research design, we can distinguish between two levels of data collection and analysis: 1) studies of the relationships between the educational level and other variables within a population, and 2) comparisons between countries.
The first approach asks thequestion, do individuals with more education have, on average, better health and healthier children that those with less education. Problems encountered in this type of research are:

How to isolate the effect of education from the effect of other factors, such as the effect of income on health. This can be done by controlling for the latter - e.g. analyzing the health status of individuals/ families and their educational level while holding constant the income level.

Relationships between variables at the individual level (e.g. persons with more education have higher income) cannot necessarily be generalized to the macro level. For instance, an increase in the average educational level of a country's population does not necessarily lead to higher national income - instead, the educational level of individuals can be a factor that influences their selection into different income-level groups.

The second approach, comparisons between countries, relates the average level of education in the population to national indicators of social development - e.g. average life expectancy and child mortality. Correlation/regression analyses are performed in a set of data drawn from a large number of countries and yield results that show the average strength of the relationship between variables. Particularly in cases where the extent of variation around the average is large, the analysis can continue to devote particular attention to individual cases. For instance, more qualitative analyses of educational conditions and health indicators have been conducted on "success stories" (e.g. Cuba and the state of Kerala in India) (Mehrotra, 1989).

\section{Effects of education via economic growth}

Education can influence social development indirectly by contributing to economic growth, which in turn creates resources for social development (through increased taxation and/ or private incomes). The actual contribution of these additional resources to social development 
4 Tuomas Takala

is further dependent on the distribution of increased income within the population, the incidence taxation among different incomeearning groups and the distribution of public social sector expenditure.

The relationship between the level of formal education and economic growth has been an enormously popular research topic since the 1960s (see e.g. Chabbott \& Ramirez, op.cit.). Much of this research has been simplistic in its assumptions and confined to statistical analysis of data on two variables: over and over again it has been shown that the level of GNP per capita at a given point in time, or growth of GNP per capita over time, and the level of formal education (average number of years completed or enrollment ratios) in individual countries are positively correlated. More recent studies have also looked at the relationship between countrylevel learning achievement (in mathematics, science and language) and economic growth rates and have found a relatively robust positive correlation (Hanushek \& Wössmann, 2007).

Studies that seek to establish a connection between the level of education and economic growth have a common limitation. They disregard other preconditions of economic growth (physical infrastructure, access to capital, credit and markets, legislation and uncorrupted implementation of legal norms, economic policies of government), in the absence of which education alone cannot generate growth (Palmer et al., 2007). Taken as a whole, the quantitative expansion of the education systems of the countries of SubSaharan Africa during their post-independence period has been more dramatic than anywhere else in history, but the economic performance of the region has been dismal. In recent decades many African countries have coupled mediumto-high rates of educational expansion with zero or even negative rates of economic growth (e.g. Tanzania, Zimbabwe). On the other hand, some countries with abundant natural resources (oil, minerals) to export, have been able to sustain economic growth even with a low educational level of their population.

\section{Direct effects of education on social development}

The effects of education are not necessarily attributable to explicit teaching of knowledge and skills, although this is the most easily visible chain of influence. Kenneth King has criticized attempts to convey to primary school pupils such knowledge that would later in life affect their behavior in desired ("modern") directions. What may well happen in reality is that such knowledge is rote-learned in order to perform in examinations, whereby "child survival knowledge gets changed into school survival knowledge" (King, 1989). In a similar vein, Bray (op. cit.) contends that the positive correlations between literacy and health might be used to support arguments for adult literacy rather than primary education for children".

Furthermore, research has shown that formal education also has significant effects through the "hidden curriculum", i.e. the school as an institution - a symbol of modernity - exerts a modernizing influence on the pupils and even on the surrounding communities, regardless of what is actually being taught and learnt in the school (op. cit.). In this respect, school-age children certainly are more susceptible to influence than adults. From the hidden curriculum perspective it also becomes understandable that formal education can have significant effects even in conditions, quite frequently found in developing countries and particularly in Sub-Saharan Africa, where the language of instruction is poorly understood by a large portion of the pupils.

Effects of formal education which have been extensively investigated by research include:

- Improved hygiene, nutrition and treatment of illness at home, and readiness to seek expert medical assistance when needed. These changes, in turn, lead to declining infant and child mortality, better health 
Contributions of Formal Education to Social Development $\mid 5$

and higher life-expectancy. Such effects have been found to be particularly linked to the educational level of women (LeVine et al., 2001; Schultz, 2002). Outstanding examples of achievements among developing countries are Cuba and Kerala, which have a much higher educational level than most other developing countries and on the health-related indicators have reached the level of the OECD-countries.

- Declining fertility. Research results in this area have often been reported in the form of: an increase of $\mathrm{x} \%$ in the educational level of the female population has the effect of reducing the fertility rate by y per cent. Such messages have, with good reason, been criticized as reflecting an instrumental view of the education of girls and women. More sophisticated research has shown that the effect of education on fertility is not linear (e.g. Palmer et al., op. cit., p. 56-57). At very low initial levels of education, some additional years of schooling may rather lead to an increase in fertility - which together with the concomitant decline in child mortality will then raise the rate of population growth. Only above a threshold level of four years of formal education does the effect of schooling become fertilitydecreasing. Furthermore, it has been established that the effects of education are dependent on the cultural context and power-relationships within families: for instance, is female employment outside home preferred to housewifery?, what is the significance of the number of children as culturally dominant symbols of femininity and masculinity?

- In the countries severely affected by HIV/ AIDS, the possibility of counteracting this pandemic through the formal education system has been given ample attention. While research evidence is mixed, the wellknown phenomenon than an increase in knowledge at the individual level about a particular health-related issue does not necessarily lead into changed attitudes and behavior is particularly obvious in the case of HIV/AIDS (e.g. Carr-Hill et al., 2002, p. 109-110, 131-2; Kelly, 2004, p. 49-58). Simplistic assumptions are also challenged by the fact that the spread of the HIV/ AIDS pandemic has been most dramatic in countries of Southern Africa, which in comparison with the rest of the continent are educationally rather advanced. At the same time, it is also evident that, independently from its other effects, primary schooling has come to serve an important social protection function, to compensate for the loss of parents and the more general weakening of social bonds due to HIV/AIDS (ADEA, 2009). In some countries, the proportion of orphans among children of primary school age may in the foreseeable future be as high as one-third! (Bennell et al., 2002)

- A more problematic question is the possible effect of education on democratic citizenship. Both individual level and crosscountry analyses have brought up a positive correlation between the level of formal education and pro-democratic attitudes (Education for All..., 2009, p. 36). But here again, several other influencing factors come into play. If the content of education is not pro-democracy, it is certainly not automatic that as the educational level of the population increases over time, the more educated people will rise up to demand and create a democratic political system (Chabbott \& Ramirez, op. cit.). Conversely, there are countries (e.g. Nepal and India) which have for decades had an established system of political democracy, coupled with a low average level of formal education in the population.

\section{Role of basic/ post-basic education in social development}

Most of the available research evidence concerns the role of primary education in contributing to the above-mentioned objectives - "the common 
Tuomas Takala

good"- which has facilitated the building of the global political consensus concerning universalization of primary education. Caillods and Hallak note that Poverty Reduction Strategic Plans (PRSPs) tend to see the potential of education narrowly as "strategies that try to integrate and retain the poor and the disadvantaged in the education system", whereby pro-poor education policy equals EFA. A broader perspective would also consider the potential of post-primary education in the development of the productive sectors and in the adoption of a more pro-poor overall development strategy (Caillods \& Hallak, 2004, p. 149).

As regards the effects of education mentioned in the previous section of this article, there are also findings showing that while primary schooling "prepares the ground", post-primary education may have a decisive effect on whether e.g. the health messages transmitted in school or the ABC of democratic citizenship are truly understood and whether the individual feels empowered to put the newly acquired knowledge into practice (Rihani, 2006, p. 27-28, 36). The average duration of schooling is thus important for the amount and kind of knowledge that can be transmitted to the students and for influencing their behavior. At the same time, expansion of post-primary education - of good quality - is severely constrained by economic realities in most developing countries.

At the post-primary levels of the education system competing interests become more obvious than at the primary level. Instead of the "common good", we must pose the question "whose social development?". For instance, the growth of female enrollment at secondary and tertiary levels can be seen either as a powerful contributor to the empowerment of women in general, or alternatively as a trend which primarily has beneficial effects for the more educated groups within society. Likewise, university education can be conceived either as a system which privileges a minority of the population, serving as a route to elite positions in the country and to emigration overseas, or which has a "developmental mission" vis-à-vis the larger society (see e.g. Coleman, 1993). These different perspectives lead to quite different conclusions regarding what is desirable educational policy and, consequently, what portions of national education budgets and of development assistance funds should be allocated to the different levels of the education system.

\section{Conclusion}

In the 1980s, reviews written by Lewin, Colclough and Little (1984) and King (op. cit.) presented agendas for further research that would in a more convincing and nuanced manner demonstrate the contribution of education to development. Lewin et al. (op. cit.) point out the need for research that would relate the effects of education on development not only to the quantity of formal education but also to its quality aspects, and that would "look to the wider society to see where changes can be made which would support current efforts of education systems to promote change". Among the more concrete research tasks proposed in this article is, for instance, that research on the effect of education on health and fertility should investigate whether these effects occur "through specific knowledge imparted through the formal curriculum of schools and/or through attitudes to the self and others imparted through the hidden curriculum and/or through a different kind of approach to out-of-school learning encouraged by exposure to general formal education". This is an important question indeed, but hardly one that could be translated into a feasible research design.

The gradual progress that has been made in the search for a contextualized understanding of the effects of formal education on social development has provided an important counterweight to the simplistic messages. The impact of critical research and discussion is seen for instance in the recent Education for All Global Monitoring Report (op. cit., p. 29), which explicitly draws attention to the wider, and politically more sensitive, societal context: "The impact of education is 


\section{Contributions of Formal Education to Social Development $\mid 7$}

strongly conditioned by other factors, from macroeconomic and labor market conditions to the state of public health provision and levels of inequality based on wealth, gender and other factors. The benefits of education are likely to be greatest in context marked by broad-based economic growth, a strong political commitment to poverty reduction, high levels of equity in access to basic services, and a commitment to democratic and accountable governance".

The PRSPs that many developing countries have been required to prepare as a precondition for debt relief and other financial support, are expected to dovetail sectoral development programs with the PRSP, based on analysis of the different sectors' potential role in poverty reduction. The above-mentioned review of the role of education in PRSPs summarized one of its findings as follows: "Education is regarded as a necessary, but not a sufficient, condition for empowerment (of the poor); other measures are required, such as information sharing, development of infrastructures, political mobilization, legal protection (Caillods \& Hallak, op.cit., p. 82)

But beyond the power of research to criticize simplistic beliefs, we must admit that the potential of research to delineate the conditions under which links between development and education are most likely to occur also has its limits, both in terms of refining theoretical understanding and providing advice to policy decisions. For further progress in this respect, the promise lies in cross-disciplinary research and a multi-sectoral approach to policy-making and planning. This, again, would require major reorientations both in the academic world and in the bureaucratic organizations of governments and donor agencies. Importantly, decisions on the allocation of funds would have to rise above rigid thinking along administrative division lines and narrow-minded competition between administrative units.

We also need to remind ourselves of the importance of listening to the order of priorities among the potential beneficiaries of development programs. If the question is formulated simply as "would you like to have a school in your village? (provided as a gift)", few people are likely to respond negatively. Instead, the more appropriate question would be, "what kind of changes in your conditions would improve your lives?", whereby the potential of formal education would be weighed against other drivers of development at the grassroots level.

\section{References}

ADEA (Association for the Development of Education in Africa) (2009). Schools as centres of care and support - responding to the needs of orphans and other vulnerable children in rural areas. Paris: Author.

Bennell, P., Hyde, K. \& Swainson, N. (2002). The impact of the HIVIAIDS epidemic on the education sector in Sub-Saharan Africa. Centre for International Education, University of Sussex (www. sussex.ac.uk/education/ documents/ aidssynpublished.pdf).

Boyle, S. (2002). Reaching the poor - the costs of sending children to primary school (www. dfid.gov.uk/Documents/publications/ reachingthepoor-edpaper47.pdf).

Bray, M. (1986). If universal primary education is the answer, what is the question? International Journal of Educational Development, 6 (3), 147-158.

Caillods \& Hallak, J. (2004). Education and PRSPs - a review of experiences. Paris: International Institute for Educational Planning (www.unesco.org/iiep/PDF/ pubs/PRSP.pdf).

Carr-Hill, R., Katabaro, J. K., Katahoire, R. A. \& Oulai, D. (2002). The impact of HIVI AIDS on education and institutionalizing preventive education. Paris: International Institute for Educational Planning. 
8 Tuomas Takala

Chabbott, C. \& Ramirez, F. (2000). Development and education. In M. Hallinan (ed.) Handbook of the sociology of education. New York: Kluwer Academic Publishing.

Coleman, J. with D. Court (1993). University development in the third world. Oxford: Pergamon Press.

Dakar framework for action (2000). Education for all - meeting our collective commitments. Adopted by the World Education Forum, Dakar, Senegal 2628 April 2000.

Education for all global monitoring report (2009). Paris: UNESCO (http://portal.unesco. org/education).

Fredriksen, B. (2009). Rationale, issues and conditions for sustaining the abolition of school fees. In B. Fredriksen (ed.) Abolishing school fees in Africa - lessons from Ethiopia, Ghana. Kenya, Malawi and Mozambique. Washington D.C.: World Bank.

Hall, A. \& Midgley, J. (2004). Social policy for development. London: SAGE

Hanushek, E. \& Wössmann, L. (2007). The Role of education quality in economic growth. Policy Research Working Paper 4122. Washington D.C.: World Bank.

Jones, P. (1988). International policies for third world education - UNESCO, literacy and development. London: Routledge.

Kelly, M. (2004). Preventing HIV transmission through education. In C. Coombe (Ed.), The HIV challenge to education. Paris: International Institute for educational Planning.

King, K. (1989). Primary schooling and developmental knowledge in Africa. Studies in Science Education 17, 29-56.
Lewin, K., Little, A. \& Colclough, C. (1983). Effects of education on development objectives, I \& II. Prospects XIII, 3, 299 311 and 4, 1983, 413-425.

LeVine, R. A. (2001). Improve the women: Mass schooling, female literacy and worldwide social change. Harvard Education Review 71 (1), 1-50.

Mehrotra, S. (1989). Health and education policies in high-achieving countries - some lessons. In S. Mehrotra \& R. Jolly (Eds.) Development with a human face - experiences in social achievement and economic growth. Oxford: Oxford University Press.

Oxenham, J. (2008). Effective literacy programmes: options for policy-makers. Paris: UNESCO, International Institute for Educational Planning.

Palmer, R., Wedgwood, R. \& Hayman, R. (2007). Educating out of poverty? Centre for African Studies, University of Edinburgh (www.dfid.gov.uk/pubs/files/ educating-out-poverty-70.pdf).

Rihani, M. (2006). Keeping the promise: Five benefits of girls' secondary education. Academy of Educational Development. (www.aed.org/publications).

Schultz, P. T. (2002). Why governments should invest more to educate girls. World Development 30 (2), 207-225.

Takala, T. (1998). Justification for and priorities of development assistance to education Finnish development cooperation in an international perspective. Scandinavian Journal of Educational Research, 42 (2).

World declaration on education for all (1990). Adopted by the World Conference on Education for All, Jomtien, Thailand, March 5-9. New York: UNICEF. 